\title{
Los partidos populistas de extrema derecha en España: Un análisis sociológico comparado
}

The far-right populist parties in Spain: A comparative sociological analysis

Víctor Climent Sanjuan* - Mirian Montaner Goetzenberger**

Resumen: En las últimas décadas los partidos de extrema derecha en Europa han experimentado un rápido crecimiento que, en algunos países europeos, los sitúa como posibles partidos de gobierno. Son formaciones políticas con un discurso marcadamente xenófobo y populista que busca beneficiarse de las debilidades de los "partidos tradicionales" para encaramarse a las estructuras de poder. En países como Francia, Holanda o Austria estas formaciones políticas han alcanzado un alto apoyo popular, mientras que en España la derecha radical, durante muchos años, apenas ha dispuesto de espacio político y su discurso ha tenido un impacto muy limitado entre el electorado. Sin embargo, desde 2018 la emergencia de VOX modifica sustancialmente el tablero político español. El presente artículo tiene como objetivo analizar los factores que analizan la dificultad y posterior emergencia de los partidos de extrema derecha en España a través del análisis de datos y de la comparativa con algunos países europeos.

Palabras clave: Derecha populista radical, Inmigración, Nacionalismo, Desigualdad Social.

\begin{abstract}
Over the last decades, extreme right parties in Europe have experienced a fast growth that, in some European countries, situate them as possible governing parties. They are political formations with a sharp xenophobic and populist discourse, which seeks benefit from the weaknesses of the "traditional parties" to climb in the power structures. In countries such as France, The Netherlands or Austria, these political formations have reached a strong popular support, while in other countries such as Spain or Portugal, the radical right barely gets political space and its discourse has very limited impact among electorates. Howewer, the emergence of VOX substantially modifies the spanish political chessboard. The objective of this article is to analyze the factors that have hindered the emergence of far-right parties in Spain through the analysis of data and the comparison with some other European countries.
\end{abstract}

Key words: Radical populist right, Immigration, Nationalism, Social inequality.

Recibido: 21 enero 2019 Aceptado:15 junio 2019

\footnotetext{
*Español, Coautor. Profesor titular del Departamento de Sociología en la Universidad de Barcelona. Email: vcliment@ub.edu

** Española, Coautora. Investigadora de la Universidad de Barcelona. Email: miriammontane@,hotmail.com
} 


\section{Marco conceptual de análisis}

Durante décadas la política europea ha estado liderada por 3 grandes familias políticas: los socialdemócratas, los demócrata-cristianos (conservadores incluidos) y los liberales. Sin embargo, en los últimos 20 años, ha surgido con fuerza un nuevo grupo político, la extrema derecha populista, que elección tras elección ha alcanzado un elevado nivel de apoyo electoral y una creciente institucionalización política, como lo demuestra la trayectoria del Frente Nacional (FN) francés o el Freibeitliche Partei Österreichs (FPÖ) austríaco, que los ha convertido en el principal enemigo a batir por parte del poder establecido o establishment. Son partidos políticos que se caracterizan por explotar sin complejos el discurso de la inmigración, del racismo o el de la "indignación social" para incrementar su perfil electoral (Acha, 2017), estan situados en el extremo derecho del arco político, aunque son claramente distinguibles de los partidos de derecha tradicional no extrema (Ignazi, 1992) y, en algunos casos, pueden llegar a ser definidos por su contenido ideológico como formaciones protesta antisistema con rasgos antidemocráticos (Minkenberg, 1997) Por otra parte, son partidos cuyo peso electoral se manifiesta de manera desigual en los distintos países europeos, aunque su influencia política es cada vez más creciente. Así, podemos observar que en Holanda (Partido por la Libertad), Austria (FPÖ), Hungría (Unión Cívica Húngara), Francia (Front National) o Finlandia (Finns Party) el auge de la extrema derecha es muy elevado, mientras que en otros países como Portugal o España su relevancia política es más limitada.

Uno de los problemas derivados del estudio de los partidos de extrema derecha (Ignazi 1992), de los partidos populistas de derecha radical (Minkenberg, 1997) o de los partidos xenófobos (Brug et al. 2003), es poderlos clasificar correctamente, puesto que son formaciones muy heterogéneas. Y aunque existen diversas maneras de clasificarlos, en este artículo seguiremos los criterios presentados por Mudde (2007), que los define como partidos populistas de derecha radical y que se caracterizan por la coincidencia de tres elementos comunes.

En primer lugar, el autoritarismo. Este concepto que alude a la creencia de una sociedad estrictamente ordenada, donde las infracciones a la autoridad deben ser severamente castigadas. Los partidos de extrema derecha muestran una gran preocupación por el concepto "ley y orden" y, a diferencia de la derecha moderada, lo expresan en términos mucho más radicales. Por otra parte, la extrema derecha tienen un marcado perfil nacionalista que no se circunscribe exclusivamente a las fronteras geográficas de país, sino que se concreta en una concepción de nación que se expresa, casi siempre, en términos étnicos, cuando no raciales y con discursos de afirmación nacionalista agresivos y esencialistas (Acha, 2017). Asimismo, otra característica común de estos partidos es la existencia de liderazgos fuertes, con estructuras de poder centralizadas que controlen las facciones internas del partido y que atraigan la atención de los medios de comunicación (Ignazi, 1992).

En segundo lugar, el populismo. Este término es ampliamente utilizado en diversos contextos y su interpretación puede variar en función del ámbito geográfico que examinemos. Por ejemplo, en el ámbito europeo el concepto se utiliza para describir a los partidos anti-inmigración y anti-UE como el Frente Nacional (FN) francés o el Partido por la Libertad holandés, mientras que en el contexto latinoamericano el populismo puede servir para aludir a la mala gestión económica o a las prácticas clientelares de determinados partidos como el Peronismo o el Chavismo (Muro, 2017). También cabe destacar que el populismo generalmente se identifica con las derechas, porque alude a las formaciones xenófobas de extrema derecha, pero también puede ser utilizado por partidos de izquierdas como Podemos (España) o Syriza (Grecia) que defienden una visión enfrentada entre "el pueblo" y "la élite" (Muro, 2017). Para una mayor claridad conceptual, el populismo puede ser definido como una ideología que visualiza una sociedad separada en dos grupos perfectamente delimitados y antagónicos, "el pueblo puro" y "la élite corrupta”, y que argumenta que la política debería ser la expresión de la voluntad general (Mude, 2007). 
El populismo en el contexto europeo se asocia a formaciones de extrema derecha que critican a la "élite corrupta" y que buscan el favor del "pueblo" que constituye la "nación" verdadera. Una característica común de la extrema derecha populista consiste en un discurso repetido hasta la saciedad de lemas xenófobos como "Primero los de casa" (FN, Francia), de mensajes anti-UE "Queremos recuperar nuestro país" (UKIP, Reino Unido) o de proclamas ultranacionalistas "Solo existe una nación" (VOX, España). Por otra parte, el populismo está directamente relacionado con la Globalización y sus efectos indeseados como: la deslocalización industrial, la creciente subcontratación y la reducción de la capacidad adquisitiva de las clases medias que ha establecido una clara correlación entre el auge de los partidos de extrema derecha y "los perdedores de la modernización y de la globalización" (Kriesi et al., 2008).

Y, en tercer lugar, el nativismo que sostiene que los Estados deben ser habitados exclusivamente por miembros del grupo nativo (la nación) y que define los elementos no nativos (personas e ideas) como una amenaza al estado-nación hegemónico (nacionalismo de características étnicas y/o culturales). Este nativismo es un "marco" que incluye una combinación de nacionalismo y xenofobia y cuyo objetivo principal es alcanzar un estado monocultural (Mudde, 2007).

Esta conceptualización nos lleva a concluir que las formaciones políticas que, con mayor o menor intensidad, incluyen en su programa estos tres elementos ideológicos pueden ser consideradas como partidos de extrema derecha populista. La ventaja de esta conceptualización, frente a otras, es que nos permite identificar a los partidos de extrema derecha que poseen más de una temática (anti-inmigración). Además, permite descartar algunos casos dudosos, como las opciones muy conservadoras, que tienden a ser valedoras de los máximos intereses del Estado-Nación, o los partidos nacionalistas con componentes claramente nativistas. En este sentido, Mudde (2007) considera que los partidos neo-nazis o neo-fascistas no forman parte de los actuales partidos populistas de extrema derecha, puesto que no cumplen con las características democráticas de los segundos, además de no existir una continuidad histórica entre la extrema derecha de entreguerras y la contemporánea (Acha, 2017).

Centrándonos en la evolución de dichas formaciones en Europa occidental, muchos autores distinguen varias fases para explicar la evolución que han experimentado desde el final de la Segunda Guerra Mundial (SGM) hasta el momento actual. Con posterioridad a la SGM, el relato del fascismo nacido en los años 30 se explica como "un mal momento, como un error histórico o alternativamente como un lapsus de barbarie dentro de la civilización" (Charalambous, 2015). Es decir, una ideología extrema incompatible con las bases fundamentales de la Europa liberal. Es lo que Mudde (2013) define como la primera oleada que se desarrolla desde el final de la SGM hasta bien entrados los años 70, siendo el partido fascista italiano MSI el principal referente de la misma y que se caracteriza por sus tendencias neofascistas y su discurso nostálgico. La segunda oleada, arranca con la irrupción en 1984 del Front National francés (FN), que impulsa un nuevo imaginario político en cuestiones como la inmigración, la seguridad nacional y el libre mercado. De esta época también provienen el Partido de la libertad de Austria (FPÖ) y el Bloque Flamenco (VB). Finalmente, la tercera oleada, se inicia con el atentado de las Torres Gemelas en septiembre de 2001, y abre las puertas a una creciente islamofobia (Norris,2009). De esta época datan la Liga Norte italiana (LN) y el Pim Fortuny holandés (LPF) y, a partir de la crisis financiera del 2008, aparece en escena un extenso grupo heterogéneo que incluye, entre otros, el UKIP de Inglaterra, Sverignedemokraterna de Suecia, Finns Party de Finlandia, Alba Dorado de Grecia y Alternativa por Alemania.

Con relación al resurgimiento del fenómeno de la extrema derecha se han llevado a cabo numerosos estudios centrados en países, en partidos o, incluso, en la relación existente entre las características de estas formaciones y sus electores. En este sentido, las teorías de la demanda y de la oferta expuestas por 
Eatwell (2003), Mudde (2007) y Kriesi (2008), junto con las aportaciones de Norris (2009) y Minkenberg (1997) permite hilvanar una serie de interpretaciones que facilitan la explicación del auge de estas nuevas formaciones políticas. Desde una perspectiva sociológica y politológica, los partidos de extrema derecha deben ser contemplados como formaciones que aceptan el marco democrático y que compiten en la arena política para captar el máximo electorado posible. Para conseguir este fin concurren factores o tesis de la "demanda", que son aquellos relacionados con el desarrollo socioeconómico, el impacto de la inmigración o los modelos de producción que aseguran el bienestar social. Y los factores de tesis de la "oferta" que implica que un partido de extrema derecha puede tener éxito electoral o no en función de variables como la estructura social del país, su sistema electoral, el espacio político o su relación con los medios de comunicación (Eatwell, 2003). Este es el orden y desarrollo teórico que seguiremos en este artículo para poder identificar las principales características de las actuales formaciones de extrema derecha populista en Europa y, muy especialmente, en España. La mayoría de estos partidos están recogidos en la tabla I, donde podemos observar el porcentaje de voto máximo en elecciones legislativas que han obtenido desde 1986 hasta la actualidad.

Tabla I. Porcentaje máximo de voto en Elecciones Legislativas de los partidos de extrema derecha radical/populistas de los países europeos occidentales desde 1986 (en \%)

\begin{tabular}{|c|c|c|c|}
\hline País & Partido (año de fundación) & $\%$ votos & $\begin{array}{l}\text { Año } \\
\text { elecciones }\end{array}$ \\
\hline \multirow{4}{*}{ Alemania } & Republikaner (REP) (1983) & 2,1 & 1990 \\
\hline & Deutsche Volksunion (1987) & 1,2 & 1998 \\
\hline & AFD (2010) & 12,6 & 2017 \\
\hline & $\begin{array}{l}\text { *Nationademokratische Partei Deutschlands } \\
(1964)\end{array}$ & 1,6 & 2005 \\
\hline \multirow{3}{*}{ Bélgica } & Vlaams Blok/Belang (VB) (1979) & 12 & 2007 \\
\hline & New Flamish Alliance (N-VA) (2001) & 20,7 & 2014 \\
\hline & Front National Belge (1985) & 2,3 & 1995 \\
\hline \multirow{2}{*}{ Francia } & Front National (1972) & 14,9 & 1997 \\
\hline & Movement national républicaine (1999) & 1,09 & 2002 \\
\hline \multirow{4}{*}{ Italia } & Lega Nord (1991) & 17,4 & 2018 \\
\hline & Fiamma Tricolore (1995) & 2,4 & 2008 \\
\hline & Movimento Sociale (1945) & 5,9 & 1987 \\
\hline & Fratelli d'Italia (2012) & 1,95 & 2013 \\
\hline Luxemburgo & $\begin{array}{l}\text { Aktionskomitee für Demokratie a } \\
\text { Rentegerchtegkeet (1987) }\end{array}$ & 11,31 & 1999 \\
\hline Países Bajos & Centrumspartij 86/Nationale Volkspartij (1986) & 2,4 & 1994 \\
\hline
\end{tabular}




\begin{tabular}{|c|c|c|c|}
\hline & Pim Fortuny List (2001) & 17 & 2002 \\
\hline & Partij voor de Vrijheid (2006) & 15,5 & 2010 \\
\hline \multirow{3}{*}{ Reino Unido } & British National Party (1980) & 1,9 & 2010 \\
\hline & National Front (1967) & 0,1 & 1992 \\
\hline & Uk Independence Party (UKIP) (1993) & 12,6 & 2015 \\
\hline \multirow{2}{*}{ Dinamarca } & Dansk Folkeparti (1995) & 21,2 & 2015 \\
\hline & Fremskridtspartie (1972) & 8,9 & 1988 \\
\hline \multirow{3}{*}{ Grecia } & Ellinko Metopo (1994) & 0,18 & 2000 \\
\hline & Laikos Orthodoxos Synagermos (2000) & 7,15 & 2009 \\
\hline & *Amanecer Dorado (1985) & 7,0 & 2015 \\
\hline Portugal & Partido Renovador Nacional (2000) & 0,5 & 2015 \\
\hline Pais & Partido (año de fundación) & $\%$ votos & $\begin{array}{l}\text { Año } \\
\text { elecciones }\end{array}$ \\
\hline \multirow{2}{*}{ Austria } & Freiheitliche Partartei Östereichs (FPÖ) (1986) & 26,0 & 2017 \\
\hline & Bündnis Zukunft Östereichs (2005) & 10,7 & 2008 \\
\hline Finlandia & Finns Party (1993) & 19,5 & 2019 \\
\hline \multirow{2}{*}{ Suecia } & Nationaldemokraterna (2001) & 0,08 & 2002 \\
\hline & Sverignedemokraterna (1988) & 17,5 & 2018 \\
\hline Noruega & Fremskrittspartiet (1973) & 22,9 & 2009 \\
\hline \multirow{3}{*}{ Suiza } & Schweizerische Volkspartei (1971) & 32,5 & 2015 \\
\hline & Schweizer Demokraten (1961) & 3,3 & 1991 \\
\hline & Lega dei Ticinesi (1991) & 1 & 2015 \\
\hline \multirow{5}{*}{ España } & Fuerza Nueva (1977-1982) & 2,10 & 1979 \\
\hline & Falange Española de las JONS (FE-JONS) (1976) & 0,22 & 1986 \\
\hline & Falange Auténtica (FA) (1979) & 0,05 & 1996 \\
\hline & La Falange (1999) & 0,06 & 2000 \\
\hline & Democracia Nacional (1995) & 0,06 & 2004 \\
\hline
\end{tabular}




\begin{tabular}{lcc}
\hline Plataforma por Cataluña (PxC) (2002) & 0,25 & 2011 \\
España 2000 (E-2000) (2002) & 0,04 & 2011 \\
Alternativa Española (AES) (2003) & 0,03 & 2008 \\
VOX (2013) & 10,26 & 2019 \\
\hline
\end{tabular}

Fuente: Elaboración propia a partir de las páginas del ministerio de interior de los diversos países

\section{Evolución en España de los partidos de extrema derecha radical y/o populista de derechas}

España, es uno de los países europeos donde los partidos de extrema derecha populista han tenido más dificultades para irrumpir en la arena política y hacerse un hueco parlamentario. En los primeros tiempos de democracia, la evolución de los partidos de extrema derecha en España está marcada por el final del franquismo y por la Transición política. En este contexto, la extrema derecha española fue incapaz de adaptarse a la nueva realidad democrática y a una sociedad que se alejaba de los valores del franquismo. Además, al no poseer liderazgo, estas formaciones muy pronto se fragmentaron y se mostraron incapaces de competir electoralmente con la Alianza Popular de Fraga Iribarne (AP) que, entre 1977 y 1979, incorporó a sus filas a muchos funcionarios del Estado de nivel medio y alto de la etapa franquista y consiguió atraer el voto conservador y temeroso con el cambio (González 2017). A partir de 1977, la Unión de Centro Democrático de Suárez (UCD) y AP consiguen englobar casi todo el espacio político de la derecha y del franquismo sociológico, que se contrapone a la minoría marginal de los franquistas inmovilistas y nostálgicos del Régimen representados por los antiguos combatientes y los jóvenes radicales de la Fuerza Nueva de Blas Piñar. Y aunque, el primer proyecto político de Fraga Iribarne (AP), consistente en unificar toda la derecha bajo unas mismas siglas, se ve abocado al fracaso por la irrupción de la UCD y la necesidad de Suárez de apartarse de la estela política del franquismo para poder ganar las primeras elecciones democráticas, ambas fuerzas políticas consiguen, entre 1977 y 1979, ocupar todo el espacio político de la derecha sin dejar el más mínimo resquicio a la extrema derecha franquista.

Con posterioridad, la implosión de UCD sólo sirve para recomponer dicho espacio político. La dimisión de Suárez por las fuertes presiones del ejército, las duras críticas de la patronal CEOE y el distanciamiento político con el Rey, da paso a un gobierno muy débil presidido por Calvo Sotelo que fracasa estrepitosamente en las elecciones de octubre de 1982 y que acelera el proceso de concentración de la derecha política bajo las siglas de Alianza Popular (Climent, 2017). En los años noventa, los partidos de extrema derecha en España tampoco supieron aprovechar la creciente crítica social hacia los sistemas democráticos europeos donde la corrupción de los partidos tradicionales, los primeros efectos económicos de la globalización y el aumento del fervor nacionalista favorece el crecimiento de la extrema derecha. Con la excepción del Grupo Independiente Liberal (GIL), que obtiene algunas alcaldías en Andalucía, la derecha populista apenas tiene protagonismo en un contexto político donde la corrupción golpea casi exclusivamente al PSOE y apenas tiene incidencia en el gran partido de la derecha española (PP).

La tercera y última intentona, se produce entrado el nuevo siglo con denominaciones como España 2000, Plataforma per Catalunya (PxC) o VOX, que fue creado a finales del 2013. Sin embargo, y aunque estos partidos obtienen algún concejal utilizando un discurso muy duro contra la corrupción y la inmigración, su peso político, como podemos observar en el gráfico1, es irrelevante hasta las elecciones de 2019 donde VOX obtiene un 10,26\% de los votos. 
Gráfico 1. Resultados electorales (votos totales y \%) de los partidos políticos populistas de derecha radical en las elecciones al parlamento europeo y en las elecciones generales en España de los últimos 16 años

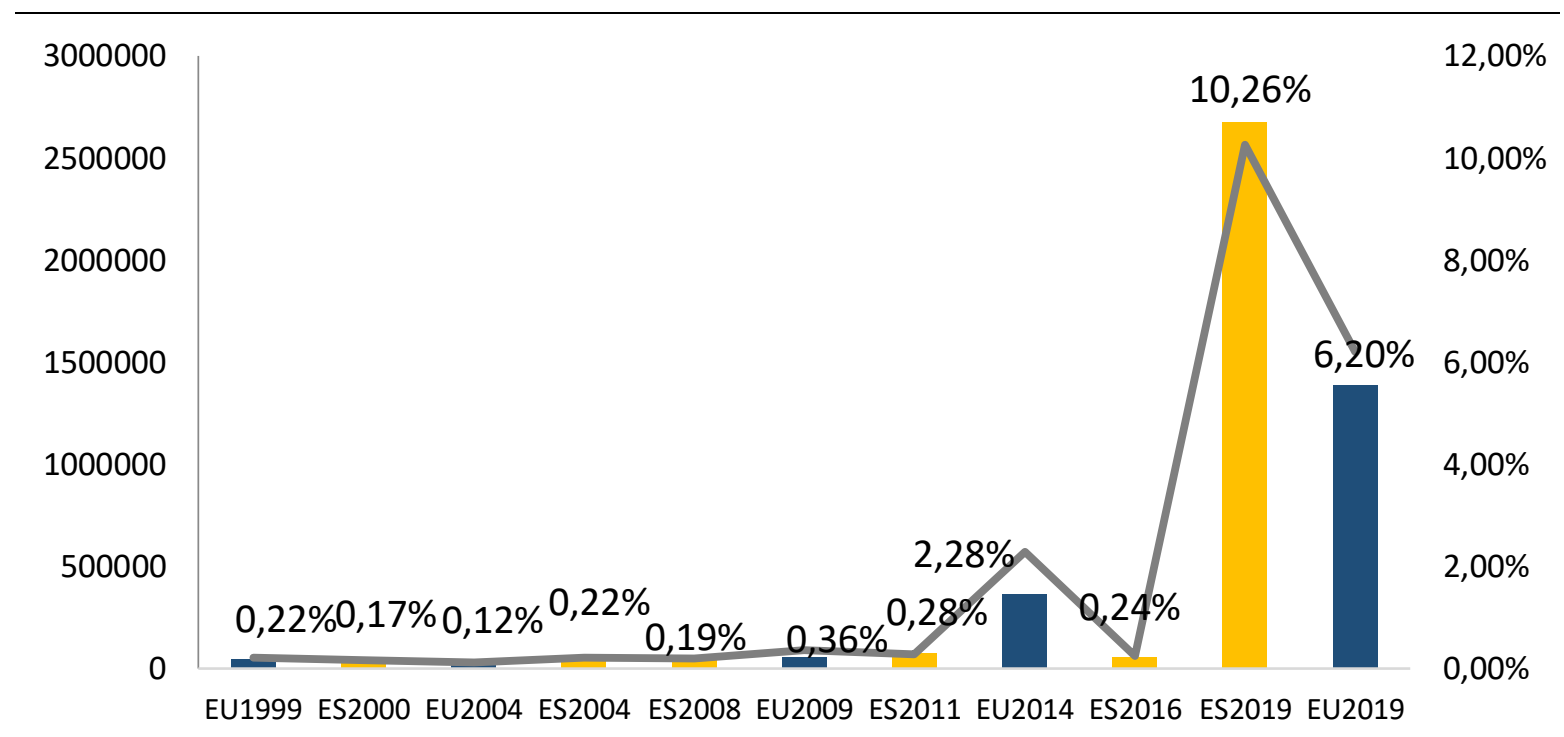

Elaboración propia a partir de los datos electorales publicados por el Ministerio del Interior Español (1999-2019) (http://www.infoelectoral.interior.es/min/)

Durante casi todo el ciclo (1999-2016) los resultados muestran un cierto incremento de votos, sobre todo, en la fase más aguda de la crisis económica (2011-2014), donde partidos como España 2000 y PxC obtienen buenos resultados en el ámbito municipal. No obstante, el saldo global es muy decepcionante puesto que en ninguna elección la suma de estas formaciones llega al 1\%, con la única excepción de las elecciones al parlamento europeo del 2014, donde VOX consigue 246.833 votos (1,56\%), pero sin obtener ningún acta parlamentaria. Sin embargo, a partir de las elecciones autonómicas andaluzas de diciembre de 2018, donde VOX obtiene un 10,9\%, se produce un cambio de ciclo que se consolida en las elecciones generales de abril de 2019 (VOX, 10,26\%) y que tiene una continuidad más modesta en las elecciones europeas de mayo de 2019 (VOX, 6,2\%). El ascenso de VOX y su entrada en los parlamentos español (24 diputados) y europeo (3 diputados) nos sitúa ante una nueva realidad política que analizaremos a lo largo de este artículo.

\section{Factores y tesis de la demanda política}

Durante años, las tesis de la demanda y la oferta (Eatwell,2003; Mudde, 2007 y Kriese et al 2008) ha sido el marco teórico que ha permitido analizar el auge de los partidos populistas de derechas en el escenario europeo de los últimos 30 años. La demanda la conformarían los electores y los factores o condiciones que generan el voto, mientras que la oferta consistiría en el ajuste de los partidos a las demandas electorales, al contexto institucional y a las reglas formales del mercado político (Norris, 2009). Y aunque esta conceptualización no siempre ha sido capaz de explicar cómo, en situaciones similares (crisis económicas, inmigración etc.), hay países donde el crecimiento de la extrema derecha es muy relevante y en otros dispone de poco espacio político, sí que permite una articulación teórica (Eatwell, 2003; Mudde 2007 y Norris, 2009) aplicable al ejemplo español. Por lo tanto, el interés del análisis y del marco teórico propuesto, consiste en desarrollar los factores explicativos por los cuales la irrupción en España de los 
partidos populistas de derecha radical ha sido mucho más tardana que en otros países con situaciones económicas y sociales similares.

\subsection{El discurso de la temática única (la inmigración)}

Uno de los temas más recurrentes de la extrema derecha populista consiste en el discurso contra la inmigración. Esto significa que, como norma general, estas formaciones deben obtener mejores resultados cuanto mayor impacto tenga la inmigración en el conjunto de la sociedad y, muy especialmente, si los inmigrantes protagonizan "actos delictivos" que atenten contra el principio de "ley y orden".

En España, un partido de temática única centrado en la inmigración, apenas ha tenido espacio político hasta el inicio de los años 2000 donde, por primera vez, se registran fuertes incrementos del saldo migratorio. Y aunque la población española sí que manifiesta una cierta preocupación en el Barómetro del Centro de Investigaciones Sociológicas (CIS) de 2007, que sitúa la inmigración como tercera preocupación $(33 \%)$, con posterioridad, esta variable no ha hecho más que decaer hasta convertirse en residual (3,2\%, CIS 2016). No obstante, sí que es cierto que la inmigración ha sido la palanca que ha permitido la irrupción electoral de algunas formaciones de extrema derecha como Plataforma por Catalunya $(\mathrm{PxC})$ o VOX. Plataforma por Catalunya es un partido que nace en 2002 y obtiene su mejor resultado electoral en las municipales de 2011 (67 concejales en la provincia de Barcelona), con un discurso que apela al sentimiento anti-inmigración (A Hernández-Carr et al., 2012) y que polariza el debate obligando a otros partidos a mantener un discurso muy duro sobre la misma, como es el caso de Albiol en Badalona (PP). En un contexto muy similar VOX, que fue fundado en 2013, tiene unos inicios muy decepcionantes con réditos electorales que apenas alcanzan el $2 \%$. Sin embargo, a partir de las elecciones andaluzas de $2018(10,9 \%)$ su suerte electoral cambia y consigue una cuota del 10,2\% en las elecciones generales españolas de 2019 y un 6,2\% en las europeas del mismo año con un rotundo discurso ultranacionalista, anti-inmigratorio y anti-feminista que aprovecha la creciente desafección política y la necesidad de incrementar la seguridad pública ante la percepción de "amenaza migratoria" que siente una parte de la población nativa sobre el "bienestar" y los "derechos tradicionales". En este sentido, los datos sobre las últimas elecciones andaluzas de 2018 son elocuentes. Como se puede observar en la tabla II, en los municipios con mayor población extranjera VOX tiene una proporción de voto mucho mayor (19$30 \%$ ) a la obtenida en el conjunto de Andalucía (10,97\%), mientras que poblaciones como Sevilla, Dos Hermanas o Carmona donde la proporción de extranjeros es baja el voto de VOX también es mucho más reducido y se asemeja a la media andaluza.

Tabla II. Municipios andaluces, tasa de extranjeros y voto a VOX en \% (2018)

\begin{tabular}{lccc}
\hline Municipio & Población extranjera \% & Extranjeros no UE \% & $\begin{array}{c}\text { Votos VOX } \\
\text { \% }\end{array}$ \\
\hline Benahavís & 63 & 20 & 19 \\
Balanegra & 22 & 15 & 30 \\
El Ejido & 30 & 23 & 30 \\
Roquetas de Mar & 28 & 17 & 23 \\
Nijar & 36 & 27 & 26 \\
Sevilla & 7 & 6 & 12 \\
Carmona & 3 & 2 & 11 \\
Malaga & 11 & 9 & 12 \\
Loja & 5 & 3 & 9 \\
Dos Hermanas & 4 & 3 & 11 \\
\hline
\end{tabular}

Fuente: Junta de Andalucía 2018 y El País (3/12/2018) 
A partir de estos argumentos parece que existen motivos suficientes para que un partido populista de derechas tenga una fuerte implantación en el ámbito español, pero ¿hay suficientes electores potenciales para este partido? Como bien sabemos hasta el 2018 no los ha habido. Sin embargo, para contestar esta pregunta con mayor profundidad, primero contrastaremos las actitudes xenófobas en España respecto Europa occidental y, posteriormente, lo relacionaremos con las variables: nativismo, autoridad, populismo e inmigración; siendo conscientes que un votante de un partido populista de derecha no tiene un solo rostro, sino más bien un marco de diferentes motivaciones. (Mudde, 2007).

\subsection{Las actitudes de los españoles ante la inmigración}

Mientras en determinados países europeos los ataques de diversa índole contra inmigrantes constituyen un hecho cotidiano, en España tales muestras de odio xenófobo han sido mucho menos frecuentes. En este sentido, algunas encuestas como el World Value Survey (2014) muestran que España está situada entre los países más tolerantes del mundo, cerca de Islandia, Canadá, Australia o Suecia y muy lejos de Alemania o Países Bajos (Inglehart et al, 2006). No obstante, estos datos pueden llevar a equivoco y ser contradictorios. Por esta razón, se contrastan con la última oleada de European Social Survey (ESS) del 2014 y se escogen tres variables dedicadas al tema inmigración: a) empeoran o mejoran la situación del país, b) enriquecen culturalmente al país o c) empeoran o mejoran la situación económica del país, en una escala de 0 (peor) a 10 (mejor).

Tabla III. Actitudes ante la inmigración de 12 países UE 2014*

\begin{tabular}{lccc} 
& $\begin{array}{c}\text { Los inmigrantes empeoran } \\
\text { o mejoran la vida del país }\end{array}$ & $\begin{array}{l}\text { La inmigración es mala o o vida cultural es } \\
\text { buena para la economía } \\
\text { del país }\end{array}$ & $\begin{array}{l}\text { La vidada onriquecida } \\
\text { socavada } \\
\text { por la inmigración }\end{array}$ \\
\hline Austria & 4,35 & 4,76 & 4,84 \\
Portugal & 4,39 & 4,98 & 5,59 \\
Reino Unido & 4,74 & 4,80 & 4,95 \\
Bélgica & 4,76 & 4,48 & 5,73 \\
Francia & 4,85 & 4,68 & 5,39 \\
España & $\mathbf{5 , 0 7}$ & $\mathbf{4 , 9 9}$ & $\mathbf{6 , 0 2}$ \\
EU (12) & 5,16 & 5,03 & 5,84 \\
Países Bajos & 5,26 & 4,87 & 6,05 \\
Irlanda & 5,33 & 4,97 & 5,38 \\
Alemania & 5,34 & 5,76 & 6,20 \\
Finlandia & 5,51 & 5,29 & 6,86 \\
Dinamarca & 5,68 & 4,94 & 5,81 \\
Suecia & 6,67 & 5,78 & 7,28 \\
\hline
\end{tabular}

Fuente: Elaboración propia a partir de European Social Survey 7 (año 2014)

Nota: 0 peor / 10 mejor

La tabla III muestra que España (respecto los 3 ítems escogidos, en 2 de ellos se sitúa por debajo de la media europea) no es un país más "tolerante" que otros países europeos, hecho que facilita que un partido "nativista" pueda tener posibilidades de institucionalización. Sin embargo, los resultados comparativos no indican si una posición favorable o negativa hacia la inmigración, predispone a que estos partidos tengan más o menos oportunidades de crecer. Sirva como ejemplo Austria y Portugal, ambos en la encuesta muestran una cierta intolerancia hacia la inmigración y, en cambio, el primero tiene un importante partido de derecha radical mientras que el segundo no. O el caso opuesto de Dinamarca, que es considerado un país tolerante, pero tiene un partido relevante de derecha radical. 
En el periodo entre 2002 y 2015, la sociedad española ha evolucionado hacia una mayor aceptación de la diferencia respecto con otras culturas (González 2017). Y aunque en estos años la población inmigrante en España ha aumentado de manera muy intensa, los datos de los Eurobarómetros de 2002 y 2015 (EB57.2 y EB83.4) muestran una evolución positiva del grado de "cercanía" hacia otros colectivos culturales o étnicos. No obstante, en España sigue habiendo personas que muestran un claro rechazo a la diversidad. Por esta razón, y para intentar averiguar si en el país existe electorado "nativista" vamos a utilizar una regresión lineal múltiple para comprobar las actitudes ante la inmigración de los españoles a partir de la encuesta ESS de 2014. Siguiendo a Zhirkov (2014), que analiza el voto de los partidos populistas de derecha en Europa y a Stöss (2010) que caracteriza al votante de derechas radical a partir de 8 características personales/contextos, se operacionan las variables en las dimensiones de las teorías que se han mencionado en el apartado anterior.

La variable dependiente (antiinmigración) se construye a partir de 3 variables sobre la inmigración (de la tabla III). La dimensión de la "desintegración social" se compone de 4 variables (Confianza política, confianza social, alineación social y ampliación UE1), la dimensión "orientación de valores" de 3 variables (Ley y orden, tradiciones, homofobia), la dimensión "económica" se divide en dos variables (problemas para llegar a final de mes y reducción de diferencias salariales) y finalmente la dimensión "ideológica" se compone de una dummy del partido político PSOE y la posición ideológica. Las características sociodemográficas se añaden como variables de control.

El modelo presentado en la tabla IV corrobora que las variables que más influyen en las actitudes positivas o negativas con respecto a la inmigración están relacionadas con la dimensión de la "desintegración social"2. La segunda dimensión, la "orientación de valores", sólo dos ítems tienen significación, en el sentido que el aumento de las variables (ley y orden y tradiciones) aumenta también el sentimiento antiinmigración. La tercera dimensión, la "económica", evidencia que no tiene tanto peso como las dos previas. Finalmente, la dimensión "ideológica" muestra que las personas que se definen de izquierdas son más tolerantes ante la inmigración. Una vez completadas las variables socioeconómicas, la educación resulta ser la variable clave para ser menos xenófobo.

La actitud ante la inmigración es una aproximación que permite señalar personas con posibles inclinaciones nativistas $y$, por lo tanto, colectivos más dispuestos a votar a un partido que incluya en su programa un discurso anti-migratorio como eje principal. A grandes rasgos, podemos identificar que la persona menos tolerante con la inmigración sería: un hombre con pocos estudios, con posiciones políticas cercanas a la derecha, que aboga por una economía liberal, tradicionalista y favorable al orden, que desea un gobierno de características autoritarias (concepto ley y orden) que ejerza un control estricto sobre la inmigración, contrario a cualquier ampliación de la Unión Europea y con poca confianza en las instituciones públicas. Esta aproximación a un posible votante de derecha radical bajo el eje nativista (inmigración), nos muestra un perfil muy similar a los estudiados en otros países de la Unión Europea donde existen formaciones políticas importantes de esta ideología. (Betz, 2003; Rydgren, 2005; Ziller y Schübel, 2015).

\subsection{La tesis de los partidos protesta}

Los numerosos casos de corrupción, la desafección creciente con los partidos tradicionales y la configuración en el imaginario popular de una élite política depredadora y extractiva, son factores clave para entender el auge de los partidos populistas de derecha radical. La animadversión hacia las políticas

\footnotetext{
${ }^{1} \mathrm{La}$ ampliación de la UE se circunscribe a la incorporación de determinados países de la UE (Rumanía y Hungría) que poseen minorías marginales como los gitanos.

2 Ello nos lo indican las "betas" que son los coeficientes estandarizados que influirán de manera más directa en la variable dependiente como mayor sea su valor (tanto positivo, como negativo) y siempre que sean significativos señalado con asteriscos).
} 
de los partidos tradicionales, el liderazgo de las televisiones como principal informador político y el creciente peso de la UE en el diseño de las políticas económicas de los países miembros, contribuye a aumentar la sensación de desamparo de algunos colectivos ante un sistema político que perciben como muy técnico y muy alejado de su propia realidad.

Tabla IV. Factores predictivos de las actitudes ante la inmigración representados betas

\begin{tabular}{llll} 
& & Betas & S.E \\
\hline \multirow{4}{*}{ Desintegración social } & Confianza política & $0,152^{* *}$ & 0,034 \\
& Confianza social & $0,176^{* *}$ & 0,043 \\
& Alineación social & 0,035 & 0,135 \\
& Ampliación UE & $0,226^{* *}$ & 0,081 \\
\hline \multirow{2}{*}{ Orientación Valores } & Ley y orden & $0,123^{* *}$ & 0,106 \\
& Tradiciones & $0,095^{* *}$ & 0,075 \\
& Homofobia & 0,034 & 0,138 \\
\hline \multirow{2}{*}{ Economía } & Gobierno debe reducir diferencias salariales & $-0,081^{*}$ & 0,111 \\
& Problemas para llegar a final de mes & $-0,012$ & 0,478 \\
\hline \multirow{2}{*}{ Ideología/Partidos } & Posición izquierda-derecha & $-0,121^{* *}$ & 0,116 \\
& Simpatizante PSOE & $-0,097^{* *}$ & 0,503 \\
\hline \multirow{2}{*}{ Socio-demográficas } & Hombre & $0,077^{*}$ & 0,402 \\
& Edad & $-0,026$ & 0,012 \\
$\mathrm{~N}$ & Nivel de educación & $0,144^{* *}$ & 0,001 \\
$\mathrm{R}^{2}$ & \multicolumn{2}{c}{} & \\
\hline \hline
\end{tabular}

** Sig Bil $\mathrm{p}<0,01 \mathrm{y} *$ Sig Bil $\mathrm{p}<0,05$ (S.E desviación estándar)

Fuente: Elaboración propia a partir de datos de European Social Survey 7 (año 2014)

En España, los partidos protesta surgen con un recorrido político bastante limitado. Generalmente, son partidos centrados en el ámbito local o europeo con líderes carismáticos que se oponen al establishment de la política clásica. Un ejemplo claro de este modelo sería el Grupo Independiente Liberal (GIL) liderado por Jesús Gil, que en 1991 obtiene la alcaldía de Marbella, y que se presenta como una tercera vía entre el PSOE y el PP o el partido "Sociedad Civil y Democracia" (2011) fundado por Mario Conde que propone el pleno desarrollo del referéndum como garante de las libertades y la soberanía ciudadana.

No obstante, el giro político de la protesta surge con mucha fuerza a partir de 2011 como consecuencia de la enorme desconfianza hacia los dos grandes partidos que han gobernado España durante los últimos 35 años. Es el resultado de una fractura generacional e interclasista que, ante la corrupción del partido gobernante PP y el seguidismo de las recetas de austeridad practicado por el PSOE, facilita la creación de una nueva formación política de izquierda radical (Podemos), que incorpora un discurso claramente populista y que obtiene 71 diputados en las elecciones legislativas de 2016 con una tipología de votante que, en otros países europeos, apoya el populismo de los partidos de derecha radical.

\subsection{La tesis de la desintegración social}

Algunos investigadores, atribuyen el auge de los partidos populistas de derecha radical a una situación de "anomia" social que transmite a muchos ciudadanos una sensación creciente de inseguridad ante el presente y el futuro. El proceso de globalización ha modificado profundamente la estructura del mercado de trabajo en muchos países desarrollados y ha introducido nuevas variables económicas y sociales que 
dificultan extremamente el acceso al mismo para muchas capas de la sociedad, especialmente aquellas que poseen pocas cualificaciones. Además, estos cambios estructurales han generado un incremento del riesgo social (Beck, 1986) y una importante pérdida de identidad por parte de los individuos (Bauman, 2002). En este sentido, los partidos populistas y radicales de derecha han sido especialmente hábiles para captar amplias franjas electorales a partir de la recuperación de los valores tradicionales, de la importancia de la "comunidad" y del valor simbólico del nacionalismo cultural.

En España la tesis de la desintegración social se traslada más al ámbito político que al social. Una de las maneras de detectarlo es a través de la participación política y, más concretamente, a partir de la desafección de los electores que, en función de los clivajes ideológicos, optan por la abstención si el partido al que ideológicamente son más cercanos no es convincente. Este hecho se puede observar en la tabla $\mathrm{V}$, que muestra la desmovilización del electorado según ideología, y que señala las opciones más cercanas al centro político como las más sensibles a la abstención.

Esta falta de confianza en las estructuras institucionales podría haber generado un posible apoyo hacia los partidos populistas de derecha radical, como ha ocurrido en otros países europeos. Sin embargo, en España el crecimiento de estas formaciones no se manifiesta hasta finales del 2018. Una de las hipótesis explicativas más relevantes para comprender este largo periodo sin la presencia de la extrema derecha consiste en la volatilidad de un clivaje clave en los partidos españoles; el "centro-periferia" que es un eje que acostumbra a polarizar a los electores (Pardos-Prado, 2012). En España, la política está marcada por el eje social "izquierda-derecha" que, a su vez, está muy influenciada por el eje nacional "centro-periferia". Así los partidos de izquierdas han sido tradicionalmente más favorables a una descentralización territorial y al reconocimiento de realidades nacionales diferentes a la española (Cataluña, País Vasco y Galicia), mientras que la derecha siempre ha sido mucho más proclive al centralismo y a la defensa a ultranza de la nación española como única realidad posible. De manera que el PP se sitúa en un extremo del eje (conservador/centralista), mientras que Podemos se sitúa en el otro extremo del eje ideológico (izquierda/descentralización). Esto explica, en parte, la dificultad que ha tenido la extrema derecha para entrar en el sistema, puesto que el espacio de los valores tradicionales, la defensa de la nación española y el centralismo político ha estado muy sólidamente ocupado por el Partido Popular.

Tabla V. Evolución de los abstencionistas según ideología en porcentaje (\%)

\begin{tabular}{cccccccc} 
& $\begin{array}{c}\text { Extrema } \\
\text { izquierda }\end{array}$ & Izquierda & $\begin{array}{c}\text { Centro } \\
\text { izquierda }\end{array}$ & $\begin{array}{c}\text { Centro } \\
\text { derecha }\end{array}$ & Derecha & $\begin{array}{c}\text { Extrema } \\
\text { derecha }\end{array}$ & $\begin{array}{c}\text { Sin } \\
\text { ideología }\end{array}$ \\
\hline 1986 & 7,6 & 4,2 & 6,2 & 5,8 & 3,6 & 3,5 & 20,1 \\
1989 & 7,1 & 6 & 9,6 & 4,2 & 4,8 & 1,3 & 22,5 \\
1993 & 5,6 & 5,6 & 8,5 & 5,4 & 3,1 & 1,4 & 20,9 \\
1996 & 7,2 & 7,3 & 7,4 & 2,2 & 2,3 & 2,7 & 15,2 \\
2000 & 13,3 & 11,1 & 8,2 & 4,6 & 3 & 3,1 & 20,1 \\
2004 & 13,1 & 11,5 & 9,7 & 22,6 & 15,1 & 8,6 & 39 \\
2008 & 11 & 8,3 & 11,4 & 18,4 & 10,6 & 8,8 & 43,9 \\
2011 & 14,9 & 12,6 & 16,1 & 16,8 & 13,4 & 8,5 & 30,3 \\
2016 & 8,4 & 11,7 & 12,7 & 14,5 & 7,5 & 9 & 35,4 \\
\hline
\end{tabular}

Fuentes: Datos de 1986-1996 (Torcal y Medina, 2001)y de 2000-2012 elaboración propia a partir de European Social Survey (ESS), oleadas 1,2,4, 6 y 8. 
Sin embargo, esta situación cambia radicalmente a partir del 2017. La evolución del proceso de independencia de Cataluña (El Procés), que inicia su andadura a partir de 2012 impulsado por buena parte de la sociedad civil catalana, a través de la Asamblea Nacional de Cataluña y Omnium ${ }^{3}$, y por el propio gobierno de Catalunya (Generalitat), culmina el 1 de octubre de 2017 con la celebración de un referéndum no autorizado por el Tribunal Constitucional sobre la independencia de Cataluña, que provoca graves enfrentamientos entre los cuerpos policiales y la ciudadanía catalana que acudió a votar. De estos hechos se derivan dos graves consecuencias. En primer lugar, la "judialización" del conflicto político entre España y Cataluña, que no es otro que la incapacidad para hallar una solución política que facilite el definitivo encaje territorial de Cataluña dentro de España. Y en segundo lugar, la clara inoperancia del gobierno de Rajoy para hallar soluciones, y que es percibido por el electorado más conservador y más nacionalista como una muestra manifiesta de debilidad política que debe enmendarse ${ }^{4}$. La posterior evolución del conflicto territorial y su "judialización" ha tensionado mucho el clivaje "centro-periferia" o "eje nacional", y ha sido uno de los factores, junto con la corrupción del partido en el gobierno y la tensión migratoria que se percibe en determinadas partes del territorio español, que más ha influido para que el electorado más derechista abra un nuevo espacio político, ajeno al Partido Popular, permitiendo a partir de 2018 la irrupción de la derecha populista y radical.

\subsection{La tesis de los intereses económicos}

En los últimos años, se ha establecido una clara correlación entre el auge de los partidos de extrema derecha y los "perdedores de la modernización y globalización” (Kriesi et al., 2008). Estos constituyen el grueso de sus votantes potenciales en un contexto donde los discursos ideológicos xenófobos se benefician de un marco histórico de pérdida gradual de soberanía de los estados-nación, de crisis económica y de altos flujos de población inmigrante (Antón-Mellón y Hernández-Carr 2016).

Generalmente, los individuos con menores recursos, poca cualificación y en situación de desempleo son más vulnerables y más sensibles a los discursos poco elaborados y directos de la derecha radical que ofrece "soluciones" a la medida de sus preocupaciones (los inmigrantes abusan de los servicios del estado del bienestar, toda la élite política es corrupta, hay que deportar a los inmigrantes que delinquen, etc...). No obstante, hay otros colectivos sociales que también pueden apoyar a la extrema derecha y son todos aquellos que experimentan sensación de pérdida de su estatus social o económico (la privación relativa). En otras palabras, el electorado potencial de la derecha radical pueden ser todos aquellos individuos cuyas perspectivas vitales estaban tradicionalmente protegidas por los limites nacionales y que perciben el debilitamiento de las fronteras como una amenaza a su estatus (Kriesi et al., 2008).

El intenso crecimiento económico registrado en España, entre 1996 y 2007, sumado al paulatino envejecimiento de la población y al incremento de la tasa de actividad femenina, ha facilitado la entrada de un gran número de inmigrantes económicos que, básicamente, se han empleado en la construcción, en el sector turístico y en el subsector de cuidados personales. Entre 2000 y 2008, España recibió la mitad de todos los inmigrantes de la UE-15 y su inmigración neta per cápita fue la más alta de la UE (González 2017). En cambio, a partir de 2008, como señala la tabla VI, la importante presencia de población no nacida en España se mantiene estable y corre paralela a un fuerte incremento del desempleo $(26 \%$ en 2013) que, indefectiblemente, ha elevado la competencia por unos recursos y un empleo cada vez más escaso. Esta realidad, ha obligado a la clase trabajadora y las clases medias a adaptarse a una nueva situación, la de perder parte de su estatus económico y social (carencia en al menos 2 conceptos) y ver

\footnotetext{
${ }^{3} \mathrm{La}$ ANC y Omnium son las dos organizaciones civiles catalanas responsables de haber impulsado las grandes manifestaciones de la Diada de Cataluña desde 2010 hasta la actualidad.

${ }^{4}$ Mientras Ciudadanos y PP piden al gobierno la nueva aplicación del artículo 155 de la Constitución a la autonomía catalana, VOX apuesta por la suspensión definitiva y la recentralización de muchas competencias autonómicas hacia el Estado.
} 
como muchos jóvenes jamás llegarán a asumir al nivel socioeconómico de los padres (tasa de paro superior al $45 \%)$.

Tabla VI. Evolución de variables que ejemplifican las consecuencias de la crisis económica en España (\%)

\begin{tabular}{|c|c|c|c|c|c|c|c|c|c|}
\hline & 2008 & 2009 & 2010 & 2011 & 2012 & 2013 & 2014 & 2015 & 2016 \\
\hline Tasa de paro & 10 & 18 & 20 & 21 & 24 & 26 & 24 & 22 & 20 \\
\hline Tasa de paro menores de 30 años & 24 & 37 & 41 & 43 & 51 & 53 & 50 & 48 & 44 \\
\hline $\begin{array}{l}\text { Tasa de extranjeros (nacidos fuera } \\
\text { de España) }\end{array}$ & 13 & 14 & 13 & 13 & 13 & 13 & 13 & 13 & 13 \\
\hline Carencia en al menos 2 conceptos $^{1}$ & 27 & 33 & 35 & 34 & 38 & 38 & 39 & 35 & 35 \\
\hline $\begin{array}{l}\text { Se prefiere contratar a un español } \\
\text { antes que a un inmigrante } \\
\text { (categoría muy aceptable y bastante } \\
\text { aceptable) }\end{array}$ & 60 & 63 & 67 & 66 & 66 & - & 62 & - & - \\
\hline $\begin{array}{l}\text { Los españoles deberían tener } \\
\text { preferencia a la hora de acceder a la } \\
\text { atención sanitaria (muy de } \\
\text { acuerdo/acuerdo) }\end{array}$ & 42 & 44 & 47 & 45 & 47 & - & 43 & - & - \\
\hline
\end{tabular}

Factores y tesis de la oferta política

\subsection{El contexto institucional}

El sistema electoral ha sido considerado como uno de los factores que, en mayor grado, puede facilitar o dificultar la entrada de todo tipo de partidos en el arco parlamentario. Se suele suponer que el sistema proporcional, en contraposición al sistema mayoritario, es un modelo que facilita una mayor implantación de estos partidos. Sin embargo, no siempre el sistema mayoritario actúa como "cortafuegos" como se constata con el Front National de Marine Le Pen que, a pesar de ser muy castigado por el sistema uninominal mayoritario a dos vueltas, consigue obtener representación parlamentaria en la Asamblea Nacional $(1997,2012$ y 2017) y en numerosos parlamentos regionales franceses. Sin embargo, sí que es contrastable que el Front National francés o el UKIP de Gran Bretaña, obtienen mucho mejores resultados en elecciones con un sistema proporcional (circunscripción única), como en las europeas de 2019 , donde el FN y el UKIP obtienen respectivamente 22 y 29 eurodiputados. No obstante, existen ejemplos contrarios en elecciones con sistemas proporcionales; Alemania, desde 1991 hasta las elecciones de 20175 no acoge a ningún partido de extrema derecha en su parlamento, mientras que Austria incorpora a la FPÖ desde los años 80. Un último aspecto a considerar de los sistemas electorales son las circunscripciones que configuran el mapa electoral; desde las circunscripciones únicas en las elecciones europeas que favorecen la irrupción de todo tipo de partidos (Front National, UKIP, Partido del Pueblo Danés o Ley y Justicia) a las circunscripciones pequeñas con pocos diputados en juego que disminuye la probabilidad de éxito de los pequeños partidos.

Otros factores que pueden favorecer o perjudicar el surgimiento de la derecha radical pueden ser: a) el propio sistema político. Un sistema federal con elecciones de diverso orden puede favorecer la irrupción de pequeñas formaciones políticas de toda índole, mientras que un sistema centralista y mayoritario lo dificulta extremadamente; b) las barreras del sistema electoral. Por ejemplo, en Alemania es necesario obtener un mínimo del 5\% de los votos o 3 diputados electos directos para que un partido pueda tener

${ }^{5}$ En las elecciones federales de 2017 la AfD obtiene un 12,6\% y 94 diputados. 
representación parlamentaria. c) Algunos países exigen a los partidos que su ideario político se adecúe al texto constitucional, como es el caso de Alemania (están prohibidos los partidos de ideología nacionalsocialista) o de España (ley de partidos de 2002 aprobada para garantizar la democracia y para castigar el entorno político de ETA).

¿Estos factores pueden perjudicar la implantación de los partidos de extrema derecha en España?

Respecto al último factor, la Ley de Partidos Políticos (ley 6/2002) que se motiva bajo la garantía del buen funcionamiento democrático y que se justifica "impidiendo que un partido político pueda, de forma reiterada y grave, atentar contra ese régimen democrático de libertades, justificar el racismo y la xenofobia o apoyar políticamente la violencia y las actividades de las bandas terroristas". Cabe decir, que dicha ley jamás ha sido aplicada a ningún partido de derecha radical y sí, en cambio, a los partidos del entorno de ETA como Herri Batasuna o el Partido Comunista de las Tierras Vascas, entre otros.

Por otra parte, la barrera electoral del 3\% tampoco impidió que Blas Piñar llegara al parlamento español (1979), aunque sí frustró la entrada en el parlamento catalán (2010) de PxC que obtuvo un 2,4\%.

Asimismo, España no tiene un sistema federal como Alemania o Austria, pero su modelo territorial descentralizado con sus respectivos parlamentos autónomos tampoco ha facilitado la irrupción de partidos de derecha radical hasta bien entrado el año 2018 y 2019 cuando irrumpe VOX en varios parlamentos autónomos españoles como el de Madrid, Aragón o Andalucía. En cambio, sí que es cierto que el sistema electoral español tiene algunas particularidades que lo hacen menos proporcional que otros países de nuestro entorno. España está dividida en 52 circunscripciones con un peso poblacional muy diferente y con una asignación de diputados muy desigual, circunstancia que favorece a los partidos mayoritarios y perjudica a los pequeños partidos de ámbito nacional.

Cabe concluir, que el efecto del marco electoral puede tener cierta relevancia con respecto a las posibles oportunidades políticas de los partidos, pero no ayuda a dar una explicación concluyente con relación al surgimiento de los partidos de extrema derecha en Europa (Arzheimer, 2009; Eatwell, 2003; Mudde, 2013).

\subsection{El contexto político}

Los partidos de derecha radical son actores que compiten por tener un espacio político propio. Es por esta razón, que la interacción entre los partidos políticos establecidos y los espacios que dejan libres por sus propias estrategias políticas es una de las claves de entrada en el escenario político (Rydgren, 2005).

Un primer factor de entrada para cualquier partido es que exista un espacio político que le permita obtener representación parlamentaria. Esto significa, que si los votantes persisten en sus lealtades con los partidos establecidos, es muy difícil que un nuevo partido tenga la más mínima oportunidad de éxito, puesto que los abstencionistas "tradicionales" y los que votan por primera vez sólo representan una pequeña parte del electorado (Ziller y Schübel , 2015).

El posicionamiento de los partidos establecidos y sus movimientos políticos es uno de los aspectos clave que puede facilitar o impedir el acceso de la extrema derecha en el espacio parlamentario. Con matices, está plenamente aceptado que, si la mayoría de partidos de un país X convergen hacia el centro, la posibilidad de entrada de otros partidos desde los extremos ideológicos será mucho mayor, como demostraron Kitscheld y McGann (1995) a propósito de la gran coalición alemana de los años 60 que proporcionó "espacio" a la NDP. O, más actualmente, el enorme hueco político que la "gran coalición" en Alemania (CDU/CSU y SPD) ha facilitado a la ultraderechista AfD, que en las elecciones legislativas de 2017 obtuvo 94 diputados. 
Un segundo aspecto, es el efecto "copia" de los partidos establecidos respecto a los partidos populistas de derechas (Minkenberg, 1997). Se argumenta que los partidos tradicionales, especialmente los conservadores han "copiado" temáticas y estilos de los partidos de extrema derecha para limitar las pérdidas electorales. En algunos casos, esta estrategia es un completo fracaso y alimenta los partidos de derecha radical (Arzheimer y Carter 2006; Eatwell, 2003). Pero, en otras circunstancias, es un éxito y el argumento sería que los partidos establecidos han sabido captar la importancia de ciertas temáticas, hacerlas suyas y que el electorado perciba que sus preocupaciones pueden ser defendidas perfectamente por la derecha tradicional. En cualquier caso, tanto si los partidos tradicionales pueden frenar o no a los partidos radicales, es innegable la influencia que éstos pueden ejercer en la agenda de los partidos mayoritarios y, muy especialmente, en las campañas electorales (Rydgren, 2005; van Spanje ,2010).

¿Qué factores políticos han podido condicionar la irrupción de un partido de extrema derecha en España?

En primer lugar, y como muestran los datos del CIS, solo una pequeña parte del electorado español se identifica con posicionamientos muy escorados a la derecha. Por lo tanto, una de las claves que ha alejado durante mucho tiempo a la extrema derecha de alcanzar representación parlamentaria puede ser la ausencia de espacio político, puesto que éste ha sido ocupado históricamente y con mucha eficacia por el Partido Popular.

Una de las características de la sociedad española es que el nivel de auto-ubicación en la escala de izquierda - derecha (1-10) se mantiene levemente inclinado hacia la izquierda (media de 4,63 en el último Barómetro del CIS octubre 2016) ${ }^{6}$ y ello se traduce en que los partidos se posicionan en torno al centro y centro izquierda para captar un mayor número de votantes. Para explicar con mayor detalle cómo se conjugan los espacios políticos en España, recurriremos a (Bakker 2018) y a la encuesta de expertos de Chapel Hill de 2014, seleccionando los 4 principales partidos políticos españoles en 2017 y comparando su posición ideológica con relación a sus potenciales votantes (CIS febrero 2019).

Gráfico 2. Posición ideológica de los partidos según expertos (2017) e ideología de sus votantes en las elecciones parlamentarias de 2019

\begin{tabular}{|c|c|c|c|c|c|c|c|c|c|}
\hline \multicolumn{2}{|c|}{ Podemos } & \multicolumn{2}{|c|}{ PSOE } & \multicolumn{4}{|c|}{ C'S - $\quad$ G PP } & \multirow[b]{2}{*}{9} & \multirow[b]{2}{*}{10} \\
\hline 1 & 2 & 3 & 4 & 5 & 6 & 7 & 8 & & \\
\hline & Votan & nos & PSOE & & & Votante & lota & & \\
\hline 1 & 2 & 3 & 4 & 5 & 6 & 7 & 8 & 9 & 10 \\
\hline
\end{tabular}

Como podemos observar en el gráfico 2, el PP cubre gran parte del espacio del centro derecha y derecha en competencia directa con Ciudadanos y, a partir de 2018, con VOX, mientras que la totalidad del arco de la izquierda y del centro izquierda se lo disputan el PSOE y Podemos. A esta ocupación exhaustiva del espacio político, cabe añadir que en España no ha habido ninguna gran coalición entre los dos partidos mayoritarios (PP y PSOE) dificultando, de facto, que ningún partido de extrema derecha pudiera tener cabida en el espacio político español.

Más allá de la existencia o ausencia de espacio político, otros investigadores señalan dos nuevos factores que hasta ahora han dificultado la irrupción de la extrema derecha. Por una parte, los lazos ideológicos de muchos votantes con los partidos mayoritarios se han mantenido estables (Tabla VII). Y, por otra

${ }^{6}$ En el barómetro del CIS febrero de 2019, la media es muy similar situándose en el 4,6. 
parte, los clivajes políticos de "centro-periferia" e "izquierda-derecha" y su correspondencia con los partidos tradicionales sigue siendo vigente en España (Alonso y Rovira Kaltwasser, 2015; Pardos-Prado, 2012). Sin embargo, esta realidad empieza a cambiar a partir de 2018.

Tabla VII. Relación entre cercanía hacia el partido con el voto real (en \%) de los dos partidos mayoritarios en España

\begin{tabular}{llllllll} 
& 2002 & 2004 & 2006 & 2008 & 2010 & 2012 & 2014 \\
\hline PP & $71 \%$ & $75 \%$ & $79 \%$ & $67 \%$ & $68 \%$ & $46 \%$ & $61 \%$ \\
PSOE & $91 \%$ & $75 \%$ & $75 \%$ & $68 \%$ & $59 \%$ & $75 \%$ & $76 \%$ \\
\hline
\end{tabular}

Fuentes: Elaboración propia a partir de la encuesta European Social Survey 2002-2014

En España, durante décadas, ningún partido de extrema derecha ha tenido la fuerza suficiente para alterar las agendas de los dos grandes partidos políticos tradicionales. Y aunque, en diversos momentos, el PP ha utilizado la inmigración como arma política contra el gobierno del PSOE e, incluso, algunos candidatos del PP han utilizado un discurso claramente xenófobo para obtener alguna alcaldía importante (Badalona 2011), ésta no ha sido la tónica general del primer partido de la derecha española.

Durante años, la polarización del discurso migratorio ha tenido poca incidencia en la sociedad española, puesto que la acción de gobierno de PP y PSOE ha actuado de barrera de contención para impedir la irrupción de partidos populistas de derecha. La escasa politización del tema migratorio, el gran peso de la inmigración de América Latina y la continuidad en las políticas migratorias de PSOE y PP ha dejado poco espacio político a los partidos de extrema derecha que han hecho bandera del discurso antiinmigratorio (Arango, 2013). No obstante, la acción de la gran crisis financiera (2008-2015) y sus consecuencias (incremento del desempleo y de la pobreza de los hogares) ha fortalecido el discurso antiinmigratorio de VOX y ha permitido que la extrema derecha alcance, por primera vez, cotas electorales importantes en determinados territorios donde hay un gran número de inmigrantes residentes (ver Tabla II, Andalucía 2018). Por otra parte, el proceso independentista de Catalunya, iniciado en 2012, ha provocado fuertes tensiones en el clivaje "centro-periferia" y ha polarizado extraordinariamente el discurso de los partidos tradicionales. Más concretamente, a partir de la votación del 1 de octubre de 2017 y la posterior causa judicial seguida contra sus líderes en el Tribunal Supremo. En este contexto, el discurso de extremo centralismo o radical nacionalismo de VOX, en contraposición a la debilidad "percibida" por la respuesta de Rajoy al problema territorial, sí que ha abierto un importante hueco electoral que ha ocupado VOX y que ha contribuido a radicalizar, aún más, el discurso territorial del PP (especialmente la nueva dirección de Casado) y de Ciudadanos. En este sentido, la extrema polarización del debate "España-Cataluña" (clivaje centro-periferia) junto con los numerosos casos de corrupción del PP han sido, sin lugar a dudas, factores principales que han permitido que VOX haya podido tener cabida en un espacio político que tradicionalmente ha estado ocupado por el PP.

\subsection{Contexto cultural}

El contexto cultural, es un aspecto clave para explicar la eclosión de los partidos populistas de extrema derecha. Por una parte, la aceptación del marco ideológico de la "nueva derecha" puede propiciar un rápido crecimiento de estos grupos políticos (Mudde, 2007: 244) y, como contraparte, un ambiente hostil o un pasado muy relacionado con periodos autoritarios o fascistas dificulta extremadamente su implantación, como sería el caso de Alemania o España. El caso español es muy claro, puesto que el abuso de los símbolos nacionales y de las referencias a la identidad nacional durante el franquismo causó un contra-movimiento que aún persiste (González 2017), aunque en los últimos tiempos éste se ha debilitado mucho por la extraordinaria polarización del clivaje "centro-periferia" introducido por el 
proceso independentista catalán. También es cierto que el apoyo de grupos de comunicación, líderes de opinión o intelectuales hacia una determinada subcultura política puede crear las condiciones sociales necesarias para que la extrema derecha eclosione, de la misma manera que la existencia de movimientos muy activos de signo contrario puede estigmatizar y bloquear la emergencia de dichos partidos.

¿España, debido a su contexto cultural, es proclive a los partidos de extrema derecha?

La Transición no supuso un cambio traumático con relación al franquismo. La opción reformista impulsada por la monarquía, las élites nacionales y los principales partidos políticos de la época, fue un ejercicio de reforma del pasado franquista como única fórmula para superar la etapa anterior y propiciar el salto hacia un sistema democrático que fuera homologable con nuestros vecinos europeos. La no ruptura mantuvo, en cierta manera, la memoria del franquismo a través de dos corrientes de derecha radical: la residual y poco competitiva Falange de las JONS y Fuerza Nueva y la derecha operativa, ágil y conservadora de Alianza Popular que supo aglutinar todo el espacio político del "franquismo sociológico" de la época (Del Rio, 2011).

Hubo un segundo momento donde el contexto cultural hubiera permitido la aparición de "nuevos partidos de derecha radical" y que se sitúa en el periodo de gobierno de Zapatero. La victoria del PSOE, después del traumático atentado de Atocha del 11 de marzo de 2004, deja al Partido Popular absolutamente desorientado y con un alto grado de radicalidad política. Además, el gobierno Zapatero impulsa determinadas iniciativas legislativas que cuestionan los valores tradicionales y que generan una enorme polarización social (ley de la memoria histórica, ley del aborto o ley del matrimonio homosexual) que, a su vez, provoca grandes manifestaciones a favor de la familia, del matrimonio heterosexual y del "olvido histórico" de la guerra civil. Estas iniciativas, impulsadas por la Conferencia Episcopal, por grupos ultra-católicos y por importantes conglomerados mediáticos, son rápidamente interiorizadas y capitaneadas por el PP que las utiliza como arma arrojadiza contra Zapatero como método para aglutinar sin fisuras al conjunto de la derecha ideológica bajo sus siglas políticas. A este contexto de radicalización social, debemos sumar la enorme polarización del clivaje centro-periferia que se ha producido en España en los últimos años, y que ha sido una constante en la historia de la democracia española. Polarización que se inicia con la campaña del PP contra el nuevo estatuto de Autonomía de Cataluña (2005), que propicia grandes réditos electorales para la derecha española, especialmente en las elecciones de 2011 (Climent, 2017), y que alcanza su máximo punto de tensión con la declaración de independencia por parte del Parlamento de Cataluña en octubre de 2017. El conflicto con los partidos nacionalistas vascos y catalanes ha sido una constante en las últimas décadas y un campo de batalla permanente que ha dejado poco espacio al debate público sobre otros asuntos (González 2017). No obstante, esta fuerte polarización de la población española que muestran los diversos barómetros del CIS (2016, 2017, 2018 y 2019) ${ }^{7}$ con relación a la organización territorial parece haber contribuido a que el electorado español pueda apoyar opciones más radicales como VOX que, hasta el 2018, apenas había tenido éxito electoral.

Con relación a la inmigración, hay que tener en cuenta que España, durante muchos periodos de su historia, ha sido un país de emigración y que la inmigración es un fenómeno relativamente nuevo que empieza a ser relevante a partir del siglo XXI. Así y todo, el importante peso que ha tenido la inmigración de América latina, con características culturales muy similares a las españolas, y la decidida implantación de un modelo intercultural por parte de las Comunidades Autónomas, ha dificultado mucho la irrupción de los partidos xenófobos. A ello, hay que añadir un gran activismo a favor de la integración por parte de organizaciones como SOS racismo, Caritas o los sindicatos CC.OO. y UGT que actúan como freno al

7 La opción de mayor centralización oscila entre el 28,2\% (2016) y el 30,9 (2018), mientras que la alternativa de mayor autonomía territorial se sitúa entre el 23,3 (2016) y el 23,1\% (2018). Centro Investigaciones Sociológicas. Barómetros 3.156 (2016), 3.191 (2017), 3.231 (2018) y 3420 (2019). 
ensalzamiento nativista relacionado con el rechazo a la inmigración. La propia matriz cultural que nace en la Transición está fundamentada en el concepto de democracia como sinónimo de modernización e incluye de forma inequívoca la noción de reconciliación (Benedicto, 2004). Este ambiente favorable, se ha plasmado en leyes de inmigración más permisivas (ranking MIPEX puesto 11) (Huddleston et al, 2015), que disminuyen la percepción de "amenaza social" de los inmigrantes y que permiten limitar mucho el campo de juego de partidos "xenófobos".

En último lugar, el papel de los medios de comunicación es fundamental para la transmisión del mensaje nativista y populista de estos partidos. Y aunque la pequeña dimensión de estas formaciones les dificulta, a veces, acceder a los espacios de alta audiencia impidiendo su visibilidad y futuro éxito (Mudde, 2007), siempre puede haber medios que pongan énfasis en titulares referidos a la inmigración, la corrupción de los partidos o el debate territorial. En este sentido, desde la primera década del nuevo siglo, se inicia una etapa mucho más proclive para el auge de estas formaciones políticas y en algunos medios se impone un discurso que relaciona directamente la inmigración con la delincuencia y se la presenta como una invasión que "esquilma los servicios sociales y que provoca un incremento de la inseguridad ciudadana", favoreciendo el crecimiento del racismo y la xenofobia.

\section{Conclusiones}

En una primera etapa, la fuerte vinculación de la extrema derecha española (Falange Jons o Fuerza Nueva) con el legado del régimen franquista contribuyó a desincentivar su irrupción y éxito electoral. Durante la Transición (1977-1982) los grupos de la extrema derecha mantuvieron un discurso muy agresivo que no aceptaba la nueva situación democrática e incluso se mostraban dispuestos a combatirla. Con el fin de la dictadura franquista, esta derecha residual no supo organizarse y su fragmentación y poca capacidad movilizadora fueron claves para su declive y práctica desaparición. Esta incapacidad adaptativa a una nueva sociedad que se aleja de los valores del franquismo facilitó que Alianza Popular pudiera posicionarse mucho mejor para captar el voto del "franquismo sociológico" de las clases medias. A partir de 1982, la desaparición de UCD acelera el proceso de concentración de la derecha política bajo las siglas de Alianza Popular (posteriormente Partido Popular), sin dar la más mínima oportunidad a que la derecha radical consolide un mínimo espacio político. Durante el gobierno Aznar (1996-2004) el PP se convierte en el partido hegemónico de la derecha y, una vez pierde el gobierno, afianza su posición ideológica a través de la defensa de los "valores tradicionales" como elemento aglutinador de la derecha ideológica. Sirva como ejemplo las iniciativas políticas impulsadas por el gobierno Zapatero a partir del 2004 (ley de la memoria historia, ley de plazos del aborto o ley del matrimonio homosexual) que provoca una fuerte contestación social seguida de grandes manifestaciones a favor de la familia, del matrimonio heterosexual y del "olvido histórico" de la guerra civil. Estas iniciativas, impulsadas por grupos ultra-católicos e importantes conglomerados mediáticos, son rápidamente interiorizadas y capitaneadas por el PP que las utiliza como arma arrojadiza contra Zapatero y como método para aglutinar sin fisuras al conjunto de la derecha ideológica bajo sus siglas políticas, impidiendo la apertura de un mínimo espacio político para la derecha radical.

Por otra parte, el sistema electoral español durante muchos años ha privilegiado a los dos grandes partidos españoles (PP y PSOE). La aplicación de la ley D'Hont, la barrera de entrada del 3\% y, sobre todo, el pequeño tamaño de muchas circunscripciones que de facto implica que solo los 2 primeros partidos obtengan representación, favorece las formaciones mayoritarias e impide que los pequeños partidos políticos puedan competir en igualdad de condiciones. No obstante, este sistema electoral deja de ser un obstáculo para la implantación de los partidos de extrema derecha, cuando éstos son capaces de elevar su representación a porcentajes superiores al 5\%. Es el caso de las elecciones andaluzas de 2018 (12 diputados con un 10,97\%), las generales de 2019 (24 diputados con un 10,2\%) o las europeas de 2019 (3 diputados con un $6,2 \%)$. 
En España la inmigración como eje de confrontación política ha tenido una incidencia modesta. A pesar de algún "experimento lepenista" llevado a cabo por el PP (Badalona 2011) o del discurso anti-inmigración de VOX (campañas electorales 2018 y 2019), la inmigración y los discursos "nativistas" han ocupado poco espacio en las agendas de los grandes partidos políticos españoles y no ha sido un factor decisivo en la irrupción de la extrema derecha. La inmigración en España es un fenómeno relativamente nuevo que empieza a ser relevante a partir del nuevo siglo. Y aunque la tensión entre autóctonos e inmigrantes ha podido facilitar la irrupción de partidos de extrema derecha xenófobos como Plataforma per Catalunya o España 2000, su incidencia electoral ha sido escasa y muy circunscrita al ámbito municipal. Además, el importante peso que ha tenido la inmigración de América latina, con características culturales y religiosas muy similares a las españolas y la implantación de un modelo intercultural claramente integrador en las Comunidades Autónomas, ha dificultado la irrupción de los partidos xenófobos y la plena aceptación de los discursos que contemplan la inmigración como una "amenaza" sobre el bienestar y los derechos tradicionales de la población nativa.

Por último, la enorme polarización del clivaje centro-periferia que se ha producido en España durante los últimos años, ha sido una constante en la historia de la democracia española. El conflicto con los partidos nacionalistas vascos y catalanes ha sido un permanente campo de batalla que ha dejado poco espacio al debate público. Esta polarización que divide a la población española (un 23,1\% pide mayor autonomía mientras que un 30,9\% reivindica mayor centralización, CIS 2018), ha sido durante muchos años un potente instrumento electoral que ha favorecido a la derecha tradicional. Sin embargo, el recrudecimiento del conflicto territorial catalán, que culmina con la declaración de independencia del Parlamento de Cataluña en octubre de 2017, es un factor importante a tener en cuenta, junto con la elevada corrupción del PP, para explicar la emergencia electoral de la extrema derecha en España. El discurso nacionalista, xenófobo y antifeminista de VOX se abre paso cuando la corrupción devora las expectativas electorales del PP y cuando más polarizada está la sociedad española con relación al conflicto territorial con Cataluña y sus posibles soluciones.

\section{Bibliografía}

Acha, Beatriz (1997). "Partidos políticos de extrema derecha en Europa. Deusto Publicaciones, 45 (2), 11 43.

Alonso, Sonia y Rovira Kaltwasser, Carlos (2015). "Spain: No Country for the Populist Radical Right?" South European Society and Politics, 20(1), 21-45.

Antón-Mellón, Joan y Hernández-Carr, Aitor (2016). "El crecimiento electoral de la derecha radical populista en Europa: parámetros ideológicos y motivaciones sociales." Política Y Sociedad, 53(1), 17-28.

Arango, Joaquim (2013). Exceptional in Europe? Spain's Experience with Immigration and Integration. Washington. DC: Migration Policy Institute

Arzheimer, Kai (2009). "Contextual Factors and the Extreme Right Vote in Western Europe , 1980 2002". American Journal of Political Science, 53(2), 259-275.

Arzheimer, Kai y Carter, Elisabeth. (2006)." Political opportunity structures and right-wing extremist party success". European Journal of Political Research, 45(3), 419-443.

Bakker, Ryan et all. (2015). 2014 Chapel Hill Expert Survey. Version 2015.1. (en linea). https://www.chesdata.eu/, útlimo acceso 12 de diciembre 2017

Bauman, Zigmunt (2002). Modernidad líquida. Madrid: S.L. Fondo de cultura económica de España, Ed.. Beck, Ulrich (1986). Risikogesellschaft. Berlin: Suhrkamp Verlag. 
Benedicto, Jorge (2004). "Cultural structures and political life: The cultural matrix of democracy in Spain." European Journal of Political Research, 43(3), 287-307.

Betz, Hans Georg (2003). "Xenophobia, identity politics and exclusionary populism in western europe." Socialist Register, 39, 193-210.

Brug, Wouter; Fennema, Meindert y Tillie, Jean. (2003). "Anti-immigrant Parties in Europe: Ideological or Protest Vote?" European Journal of Political Research, 37(1), 77-102.

Cea D’Ancona, Mará Ángeles y Valles Martinez, Miguel S. (2014). Evolución del racismo,la xenofobia y otras formas conexas de intolerancia en España. Informe Encuesta 2014. Madrid: Ministerio de Empleo y Seguridad Social.

Centro de Investigaciones Sociológicas. Barómetros mayo 2007 ( $\mathrm{n}^{\circ}$ 2801), octubre 2016 ( $\mathrm{n}^{\circ} 3156$ ), octubre 2017 (n 3191), noviembre 2018 (n 3231) y febrero 2019 (n 3240). Madrid: Informe Explotación Banco de Datos del CIS.

Charalambous, Giorgios (2015). The European Far Right: Historical and contemporary perspectives. Nicosia: PRIO Cyprus Centre.

Climent Sanjuán, Victor (2017). Estructura social de España y Cataluña (Vol. 242). Barcelona, Universitat Barcelona.

Comisión Europea (2002), Eurobarómetro 57.2.

Comisión Europea (2015), Eurobarómetro 83.4.

Del Rio Morillas, Miguel Àngel (2011). "La extrema derecha neofranquista a inicios del postfranquismo." Miscel-lania, IX, 92-106.

Eatwell, Roger (2003). "Ten theories of the extreme right." En: Merkl, Peter H. y Weinberg, Leonard (eds), Right-wing Extremismus in the Twentiyfirst century. Londres: Routledge.

González, Carmen (2017). "La excepción española". Real Instituto Elcano (online). http://www.realinstitutoelcano.org/wps/portal/rielcano es/contenido?WCM GLOBAL CONTEXT =/elcano/elcano_es/zonas es/dt7-2017-gonzalezenriquez-excepcion-espanola-fracaso-gruposderecha-populista, último acceso 16 abril 2018

Hernández-Carr, Aitor (2013). "El salto a la nueva extrema derecha: Una aproximación a los votantes de Plataforma per Catalunya." Politica Y Sociedad, 50(2), 601-627.

Hernández-Carr, Aitor; Aramburu, Mikel y Mellón, Juan Anton. (2012). La Irrupción de la nueva extrema derecha en España Un análisis de la trayectoria, estrategia politica y base electoral de Plataforma per Catalunya. Universitat Autónoma de Barcelona. (en linea) http://ddd.uab.cat/record/103638/, último acceso 23 de abril 2016.

Huddleston, Thomas et all. (2015). Migrant Integration Policy Index 2015. Igarss 2014 Barcelona/Brussels: CIDOB.

Ignazi, Piero (1992). "The silent counter-revolution". European Journal of Political Research, 22(1), 3-34.

Inglehart, Ronald; Moaddel, Monsoor y Tessler, Mark. (2006). "Xenophobia and In-Group Solidarity in Iraq: A Natural Experiment on the Impact of Insecurity." Perspectives on Politics, 4(3).

Kriesi, Hanspeter et al. (2008). West European Politics in the Age of Globalization. Cambridge: Cambridge University Press.

Langenbacher, Nora y Schellenberg, Britta (2011). Europa Auf dem "Rechte" Weg? Rechtsextremismus Und 
Rechtspopulismus in Europa. Berlin: Friedrich-Ebert-Stiftung.

Minkenberg, Michael. (1997). "Die Neue Radikale Rechte Im Vergleich?: Frankreich Und Deutschland." Zeitschrift für Parlamentsfragen 28(1):140-59.

Mudde, Cas (2007) Populist Radical Right Parties in Europe. Cambridge: Cambridge University Press.

Mudde, Cas (2013) “Three Decades of Populist Radical Right Parties in Western Europe: So What?" European Journal of Political Research 52(1), 1-19.

Muro, David. (2017). "Dejemos que la gente gobierne" en "El populismo en Europa: ¿De síntoma a alternativa?". CIDOB Report \# 01.2017, 9-13. Barcelona

Norris, Pippa (2009). Derecha radical: Votantes y partidos en el mercado electoral (Vol. 287). Madrid: Ediciones Akal.

Pardos-Prado, Sergi (2012). "The Electoral Effect of Immigration Preferences and the Centre-Periphery Cleavage in Spain.” South European Society and Politics October (January 2015):1-16.

Rydgren, Jens (2005). "Is Extreme Right-Wing Populism Contagious? Explaining the Emergence of a New Party Family.” European Journal of Political Research 44(3):413-37.

Stöss, Richard (2010). Rechtsextremismus Im Wandel. Berlin: Friedrich-Ebert-Stiftung.

Torcal, Mariano y Medina, Lucia (2001). "Ideología y voto en España 1979-2000: Los Procesos de Reconstrucción Racional de La Identificación Ideológica." Revista Española de Ciencia Política 6:57-96.

Van Spanje, Joost. (2010). "Contagious Parties: Anti-Immigration Parties and Their Impact on Other Parties' Immigration Stances in Contemporary Western Europe.” Party Politics 16(5):563-86.

Zhirkov, Kirill (2014) "Nativist but Not Alienated: A Comparative Perspective on the Radical Right Vote in Western Europe." Party Politics 20(2), 286-96.

Ziller, Conrad y Schübel, Thomas (2015). “'The Pure People' versus 'the Corrupt Elite’? Political Corruption, Political Trust and the Success of Radical Right Parties in Europe." Journal of Elections, Public Opinion and Parties (July 2015), 1-19. 